\title{
Use of iPads in the Education of Children with Autism-Spectrum Disorder
}

\author{
Roman Yavich $^{1} \&$ Nitza Davidovich ${ }^{2}$ \\ ${ }^{1}$ Department of Mathematics, Ariel University, Israel \\ ${ }^{2}$ Department of Behavioral Sciences, Ariel University, Israel \\ Correspondence: Roman Yavich, Department of Mathematics, Ariel University, Israel. E-mail: \\ romany@ariel.ac.il
}

Received: October 3, 2019

Accepted: November 1, 2019

Online Published: November 16, 2019

doi:10.5539/hes.v9n4p214

URL: https://doi.org/10.5539/hes.v9n4p214

\begin{abstract}
The purpose of this study is to investigate the effect of iPads on children with autism-spectrum disorder (ASD) in three areas: quality of learning, communication skills and social skills, and to determine whether there are any negative effects. We found many studies on this topic. To answer this question, we sent an online questionnaire to past and present special-education staff. The questions were retrieved from two questionnaires-"Ha'arakhat Proyekt Mihhshuv Ganim Liladim 'im Tsrakhim Meyuhadim" (The Assessment of Creating Computer Environments in Special-Education Kindergartens) (1997) and "'Emdot Morim Klapey Shiluv Tekhnologyot Meda IT Behora'a" (Teachers' Attitudes Toward Integrating Information Technology [IT] into Instruction) (2016) The sample population included 100 subjects, 95 of which were women and 5 were men, of various occupations. The most significant occupations were: National Service ("Sherut Leumi", an alternative voluntary service for young Israelis exempt from serving in the Israel Defense Forces), teacher, and teaching assistant. The hypotheses concerning communication and learning were proved-the iPad was found to aid and improve communication and learning in children with ASD. The hypothesis concerning social skills was disproved-iPads were found to improve social skills. The hypothesis concerning the negative effects of iPads was proved as well, and a positive correlation was found; that is, the more the iPad is used, the greater are its negative effects, specifically outbursts and iPad obsession. The conclusion is that the use of breakthrough technology in special education brings significant change into the lives of children with ASD, despite its clear disadvantages.
\end{abstract}

Keywords: ASD, autism, iPad, special education

\section{Introduction}

In recent years, the Israeli education system has undergone many transformations: new approaches were introduced, new tools have been developed, new methodologies have replaced the old ones, and teaching methods and technologies that were not accessible in special-education schools or even in regular schools are now being used. This revolution has already profoundly changed the lives of people with disabilities, and there is no doubt that it will continue doing so in the future.

The special-education system has improved, over the past decade, using innovative means of communication that enable interpersonal communication and optimal learning for children with autism-spectrum disorder (ASD). Some of these means are technological, such as the iPad, which is used today as a significant learning and teaching aid in the special-education school frame. Because the iPad is a normative and popular tool, it enhances a feeling of belonging and social integration. In addition, it can be used collaboratively and serve as an aid in various collaborative activities.

The iPad is already used as a means of alternative communication in place of the various communication boards. It includes various features that are specially designed and adapted for people with disabilities. In addition, it doesn't distinguish the person with disabilities-on the contrary; as an attractive and popular tool that everyone uses, it can even encourage integration and collaboration.

There is no previous research that uses questionnaires to examine the approach of teachers toward the use of iPads. Most of the research that we found was conducted based on experiments. In this research, we examine the approach of special-education staff toward iPad usage and the effect of iPads on autistic children in the 
special-education system.

\section{Previous Literature}

\subsection{Autism}

Autism is defined as a neurodevelopmental disorder characterized by prominent deficiencies in three areas: language and communication; reciprocal social ability and social contact; and restricted behavior, as well as restricted interests and repetitive preoccupation with them. There is a wide range of disorders that are known today by the generic name "autism-spectrum disorders". These disorders range from less to more severe (Gorbatov \& Ben-Moshe, 2019).

Every person diagnosed with ASD is unique, and there are no two who are alike. The autism spectrum includes the following disorders: classic autism/ autistic disorder, Asperger syndrome, pervasive developmental disorder not otherwise specified (PDD-NOS), childhood disintegrative disorder and Rett syndrome (Gorbatov \& Ben-Moshe, 2019).

The impairments are in three areas:

1. Language and communication-verbal and nonverbal. A delay in language development and a lack of compensating nonverbal communication is usually reported.

2. Social skills-impairment in the ability to create interpersonal contact, communicate emotions and understand other people's emotions, and impairment in shared attention that requires communicative eye contact and facial expressions.

3. Behavioral patterns-a wide range of impairments, including impairment in playing skills, stereotypical repetitive behaviors and cognitive problems, as well as behavioral characteristics that interfere with day-to-day functioning-problems with attention and concentration, overfocus, hyperactivity and more. In addition, some of the children may show special abilities beyond the normal at their age, such as a phenomenal memory for places and dates, memorization of trivia, high mathematical abilities, musical abilities, drawing abilities and visuospatial skills such as solving puzzles and road orientation (Gorbatov \& Ben-Moshe, 2019).

Until the 1990s, the common approach was that $70 \%$ of children with ASD suffer from a certain degree of developmental delay (intellectual development disorder). Recently, there are more children at a cognitively normal level that are included in the autistic spectrum (Evyasar, Ehrlich, Heiman, \& Ronen, 2015).

Some children with ASD show aggression toward their environment and even self-injurious behavior. A child's resistance to change may cause him to react with frustration and throw himself angrily on the floor. Many children with ASD show symptoms of anxiety, and sometimes even a lack of motivation and an indifference to their surroundings. Some of them also suffer from motor coordination problems and experience difficulty in motor planning. Epilepsy may break out, especially during adolescence (Evyasar et al., 2015).

Today, wide agreement has been reached that ASD is a neurodevelopmental disorder with a genetic basis, possibly also caused by environmental factors. The cause of autism is still unknown. Existing research reports a high incidence in identical twins (60-90\%) compared to fraternal twins (0-5\%). In addition, research has been conducted on the levels of serotonin, and people with ASD were found to have irregular levels of the hormone. A strong correlation with heredity was also found (Evyasar et al., 2015).

There are many therapeutic programs that can be used to treat ASD, including:

- Applied behavioral analysis (ABA)-a behavioristic approach that is based on learning principles developed according to behavioristic psychological theories.

- The developmental, individual-differences, relationship-based (DIR) model-a developmental approach that was developed to help children with ASD reach a sense of personal capability as well as cognitive, language and social abilities.

- The early start Denver model (ESDM)-according to this approach, the focus is on creating social-interaction situations with the child that will develop his imitation, play and interpersonal-communication skills while attaining the developmental stages that children with autism lack.

- The University of North Carolina program for the treatment and education of autistic and related communication handicapped children (TEACCH)-a central goal of this program is to improve the child's skills through his fields of interest and adapt the environment to the unique needs arising from his handicap.

Other programs include paramedical treatment, medication and various therapies (Evyasar et al., 2015; Lord \& Bishop, 2010). 


\subsection{The Special-Education System}

In 1988, after years of failed attempts to answer the needs of special children in the regular education system, the Special Education Law was first introduced, which states that children with special needs are eligible to receive special-education services from the age of three to twenty-one. The special-education system addresses the therapeutic and learning needs of each individual according to his needs and difficulties (Waisblay, 2015).

During the special-education hours, the children receive various treatments. In accordance with the law, all children diagnosed with autism who are enrolled in special education institutes are eligible for paramedical treatment, including physical therapy, occupational therapy, speech-language therapy, dance therapy, and music therapy. The treatment hours can used for individual therapy, group therapy or staff training (Sharon, 2010).

The individualized education program (תל"א) is set at the beginning of each school year for each student individually. The program includes the student's level of functioning, as well as learning goals and objectives, the time period for achieving them, the means needed to achieve them, and ways of assessment. The program is built in collaboration with the parents and the student, if possible. The additional education program (תל"ו) includes extracurricular school-work and activities (Sharon, 2010).

In educational institutions for students with autism, the law states that each class should include 5-8 children and an educational staff consisting of a special-education teacher and a teaching assistant. The number of children is determined by a special-education superintendent after taking into account the students' academic and social needs, county budget considerations, and classroom-population guidelines, as determined by the pedagogical director (Sharon, 2010).

\subsection{IPads}

An iPad is a computer consisting only of a touch-screen, which operates at the touch of a finger or special pen in place of a mouse and keyboard. The iPad is accessible and can be carried from place to place. It has various advantages: an easy-to-use touch-screen, screen-size settings, controllable multimedia playback (by another computer), significant volume, and various data-collection capabilities (Ostashewski \& Reid, 2010).

The emerging technology and more positive social regard toward people with disabilities provide professionals with a variety of new ways to enhance the quality of life of people with disabilities. The iPad, which is a technological tool used in normative life, opens new options for people with ASD in various areas of life, thereby promoting equal rights. It enables active participation and promotes a sense of belonging and social integration, first and foremost by being a normative popular tool (Nitsan, 2015).

Normativity and popularity: The iPad is used as an auxiliary device whose appearance and use are unexceptional. This makes it easy for families to purchase the device and learn how to use it, and also encourages them to use it. The fact that the iPad is unexceptional and popular also has great importance for users of all ages, who enjoy a feeling of social belonging by using it.

Mobility: The device is relatively lightweight and convenient to carry around, thus enabling widespread use in many environments.

Instant and meaningful feedback: Every touch on the iPad screen results in an action, thereby allowing people with various disabilities to use it, enhancing the sense of self-efficacy and increasing the motivation to use it.

Accessibility: The iPad has built-in accessibility features and is easy to operate.

High quality: The device meets very high standards, for example, high screen resolution suitable for use by people with disabilities.

Variety of applications: Various applications can be easily and instantly downloaded to a single device. Applications for children with special needs can be found in Apple's app store (Nitsan, 2015).

The great advantage of iPads is in allowing quick communication and accessibility. The accessibility and availability of the iPad helps with collaborative work and enables the continuity of learning even after school hours. Each child's learning can be tailored to his needs using the various apps. The iPad creates a personalized learning environment and helps make learning more interesting, relevant and accessible to children (Manny-Ikan, Berger-Tikochinski, Bashan, \& Wolf, 2015). Using the iPad as a learning aid for those who have difficulty reading and writing helps people with disabilities get organized and also serves as an aid for play (such as applications used as a replacement for a cube or spinning top) (Nitsan, 2015).

Various studies suggest that the iPad may weaken the distinction between traditional learning and everyday learning that takes place anytime and anywhere the student chooses.() Furthermore, effective use of the iPad in 
the education system may enable mediation between formal and informal education and help the student to create a natural cohesive learning environment for himself. With the iPad, everyday life and study become one (Manny-Ikan et al., 2015).

The technology used in iPads is usually on a smaller scale and less expensive than most traditional augmentative and alternative communication (AAC) devices. The fact that everyone uses iPads takes the focus off the user's disability. There is a worldwide revolution in the individualized lives of people with various disabilities, and this can be seen in the lives of people on the autistic spectrum (McNaughton \& Light, 2013).

\subsection{The Use of Technology in the Education System}

The rapid technological development and its growing influence on individual life and society have led to a wide recognition of the need to instill technological knowledge and the ability to use technology in every graduate of the education system. The Israeli education system makes great efforts to innovate and expand scientific-technological education from early childhood to high-school graduation and provide technology education for all students. There is a new approach called "science, technology and society" (STS), which is distinctly different from the classic traditional concept of vocational education that usually targets students with low educational achievements (Barak \& Peleg, 1998).

There are those who argue that technological education is necessary for everyone and may reduce educational and employment gaps in Israeli society. In addition, technological education prepares the children for the world of tomorrow. Changes and processes are taking place in Israel and the Western world, moving from vocational education, whose main focus is preparing part of the high-school-aged population for jobs, to scientific-technological education, which is seen as an essential and important component in the general education of all students (Barak \& Peleg, 1998).

Innovative learning technologies create opportunities that promote thinking, thereby challenging current learning and understanding methods. These technologies are based on a wide range of online information, technological tools, and innovative learning strategies. The technology serves learners as an intellectual partner that helps advance thinking, learning and understanding of the world in which we live. Learning with technology may promote significant learning if it is based on the learners' involvement in building knowledge, conversation, self-expression and reflective thinking (Cohen, 2015, Davidovitch, Yavich, \& Keller 2014).

Online learning is aimed at learners' involvement in the learning process and high-order thinking in a collaborative process of creating knowledge with their colleagues. There is a wide range of technological tools that can be integrated into the learning processes, such as the interactive whiteboard, computer and iPad (Cohen, 2015).

\subsubsection{The Use of iPads in the Education of Children with ASD}

Many studies have investigated the use of iPads among children on the autistic spectrum. The use of iPads was found to facilitate communication between teachers and students with ASD, including those who need an alternative AAC communication estimate. In addition, the iPad was found to serve as a significant tool for communication, as well as a tool to acquire academic reading, writing and math abilities (Alhajeri, Anderson, \& Alant, 2017).

Students with ASD often present behavioral problems. In a study on using iPads as a means of working on behavioral problems, Gould examined whether it is possible to monitor the behavior of students with ASD through iPads and, consequently, improve their academic performance. The behaviors examined were: direct looking toward the front of the classroom, looking at the teacher, engaging in a task and sitting in place (Gould, 2015).

All students showed improvement in behavior, but when their iPads were taken from them, their behavior during task performance worsened. When the iPads were returned to them, their behavior improved. Significant improvement was found at the behavioral level, and less prominent improvement at the academic level. This study shows that students with ASD are able to improve their behavior during tasks using a self-monitoring system on their iPads (Gould, 2015).

Today, there is a major model that guides health professionals-the international classification of functioning, disability and health (ICF) model. This model highlights the importance of human participation in community integration as a significant variable. Rather than focusing on a person's limitations, the model addresses his capabilities and guides professionals to find ways that can help him integrate into his social environment by providing tools and creating a tailored environment. The iPad is used as a significant tool for implementing this model (Nitsan, 2015). 
The iPad serves as a speech-generating device (SGD) for children with ASD and limited speech. In a study that investigates the use of iPads for improving academic skills, the researchers tested the ability of people to match an image to a word and vice versa. Four modes were tested: word-to-word, picture-to-picture, word-to-picture and picture-to-word. The matching was done on iPads. The results show high levels of successful responses (Van der meer et al., 2015).

The study examines whether there is any advantage in using iPads as a tool for acquiring narrative abilities in children with ASD. Children need these skills to achieve social and academic success. The ability to tell a story has the potential to develop imagination and inspiration, enhance verbal fluency and verbosity, improve public-speaking abilities, enhance learning abilities, encourage children to write and, ultimately, create as normative a life as possible (Vicegreen, 2017).

In the study, picture books are compared with iPad books. The participants were asked to browse book or iPad pages and become acquainted with the story in the book or iPad. Then, they were asked to tell the story while looking at the pictures. The results of the study show that the children with ASD received higher scores using iPads, compared to using picture books. From this study, the iPad can be deduced as a source of motivation for learning in this population (Vicegreen, 2017).

Burton, Anderson, Prater, and Dyches examined how self-monitoring videos can improve the math abilities of children with ASD. This method is called video self-modeling (VSM). The videos present mathematical problems in which the children appear. Through the videos, the children learned to tell time, as well as basic mathematical activities including paying money for a product or service and receiving change. The results of the study show that, using this method, there was improvement in learning.

Another study examines the difference in communication in children with ASD when using the iPad rather than the picture-exchange communication system (PECS). The PECS is used as a communication board that displays images of various items. By showing a picture or pointing to it, the user expresses himself. Using the PECS improves social communication and play, and reduces the number of behavioral outbursts. The educational staff claimed that the children enjoyed the iPad and it even induced faster communication. In addition, it was easier for the children to use the iPad (Flores et al., 2012).

The results of the study show that some students experienced significant improvement in communication and, for others, the level of communication remained unchanged. In addition, the researchers found a number of disadvantages to using iPads. They suggest that eye contact and attracting people's attention may be better using the PECS rather than an iPad. Another drawback is that the iPad needs to be touched in a specific and precise manner to work properly, which can be difficult for children with ASD (Flores et al., 2012).

Another study on the subject investigates the goals of using iPads, and if and to what extent the use of iPads is effective and promotes learning. It was found that iPads have a number of possible uses. Three types of applications can be used on iPads: language applications, educational applications, and games. The study shows that children used the applications correctly $69 \%$ of the time. When a professional was near a child, the correct use of the applications increased. The applications with the highest percentage of correct usage are the games, next are the educational applications, and in the last place are the applications used for communication. It was found that only $13 \%$ of the time iPads were used as a boost or to take a break (King, Thomeczek, Voreis, \& Scott, 2014).

The use of iPads to improve the ability of autistic children to take turns in games was examined. It was found that iPads improve playing skills and decrease the number of problematic behaviors. The researchers suggest using iPads as an effective tool for socialization and, especially, taking turns. Taking turns in games is a significant element in the initial work with children with ASD, because it is considered an initial framework of early learning. In addition, the behavior of children when taking turns was found to be associated with early-childhood social acceptance. A simple application makes it is easier to tailor intervention techniques to each child's characteristics, track the child's progress, and provide him with clear instructions (Clarke \& Kim, 2015).

In previous studies, small population groups were tested, and most of the studies were based on experiments. The experiments examined the effect on learning assimilation and improvement in the quality of learning and communication in children with ASD.

In our study, we examine the effect of iPad usage in the special-education system on children with ASD. We examine the educational staff's viewpoint on the effect of iPads on the children. This is done by using questionnaires ("Ha'arakhat Proyekt Mihhshuv Ganim Liladim 'im Tsrakhim Meyuhadim" [The Assessment of 
Creating Computer Environments in Special-Education Kindergartens] 1997; "'Emdot Morim Klapey Shiluv Tekhnologyot Meda IT Behora'a" [Teachers' Attitudes Toward Integrating Information Technology (IT) into Instruction], 2016). Our goal is to examine the effect of iPad usage in the special-education system on children with ASD in terms of communication, learning and social abilities.

\section{Research Questions}

1. In what ways does the use of iPads improve communication skills?

2. How does learning change and improve by using iPads?

3. Does using iPads increase social capabilities?

4. Are there any disadvantages to using iPads?

\subsection{Research Hypotheses}

1. The educational staff will report improvement in children's communication.

2. The use of iPads improves learning, but there are differences between the various levels.

3. The use of iPads negatively affects social abilities.

4. There are negative consequences of using iPads, including outbursts, iPad obsession, and lack of communication with the surrounding environment.

\section{Method}

\subsection{Sample}

The research population is the staff who works with children on the autistic spectrum using iPads, within the special-education system. In this study, 100 subjects participated, 95 of which were women and 5 were men. Most of the staff are university or college graduates: bachelor's degree $(\mathrm{N}=45)$ and master's degree $(\mathrm{N}=21)$. Furthermore, 34 of them only received secondary education. The sample includes subjects of various occupations. The most significant jobs are National Service ("Sherut Leumi", an alternative voluntary service for young Israelis exempt from serving in the Israel Defense Forces) $(\mathrm{N}=31)$, teaching $(\mathrm{N}=29)$ and teaching assistant $(\mathrm{N}=14)$. Other jobs and occupations include behavior analyst $(\mathrm{N}=13)$, university or college student $(\mathrm{N}=9)$, occupational therapist $(\mathrm{N}=3)$, and speech-language therapist $(\mathrm{N}=1)$. Moreover, most of the participants reported being in their job for one to five years $(\mathrm{N}=52)$. Because the total number of subjects is 100 , the number of subjects in each job is the same as the percentage of subjects. In addition, 20 participants reported being in their job between five and ten years, and 18 reported being in their job for more than ten years. Only 9 participants reported being in their job for less than a year.

\subsection{Research Tools}

For the research, questionnaires were used. Some of the questions were taken from the questionnaires "Ha'arakhat Proyekt Mihhshuv Ganim Liladim 'im Tsrakhim Meyuhadim" (1997) and "'Emdot Morim Klapey Shiluv Tekhnologyot Meda IT Behora'a" (2016). The questions were based on previous literature and on the research questions. The proposed sampling method is snowball sampling.

\section{Procedure}

The study was approved by the Institutional Ethical Committee at Ariel University. The subjects volunteered to participate in the experiment and were not rewarded for their participation in the study. The questionnaires were sent to the subjects using Google Docs and via social networks (WhatsApp, Facebook). The questionnaire is preceded by a declaration of the participants' confidentiality and anonymity, and the possibility to stop at any time, as well as ways to contact the researchers. The participants answered the questionnaires, and were given no time limit. All the responses were collected on the Google Docs website and then directly passed on to an Excel table and copied for statistical analysis.

\section{Results}

From the questionnaires, we created five categories on which the research hypotheses were based and the statistical tests were performed:

Level of usage. The extent to which the iPad is a useful tool for children in school (questions 1, 3, 5, 7, 9, 11, 17, 28). Cronbach's alpha reliability was found to be medium-high (0.683). A high score in the variable indicates high use of the iPad.

Communication. The extent to which the iPad helps children develop communication skills (questions 4, 12, 15, $16,25)$. Cronbach's alpha reliability was found to be medium-high (0.679). A high score in the variable indicates improved communication as a result of using the iPad. 
Learning. The extent to which the iPad helps children learn (questions 6, 13, 14, 19, 20, 21, 30). Cronbach's alpha reliability was found to be high (0.840). A high score in the variable indicates improvement in learning as a result of using the iPad.

Social skills. The extent to which the iPad affects the child's social relationships (questions 23, 24, 29). Cronbach's alpha reliability was found to be moderate (0.569). A high score in the variable indicates improvement in social skills as a result of using the iPad.

Disadvantages of iPads. The extent to which iPads cause difficulties for children who use them (questions 8, 10, $18,22,26,27)$. Cronbach's alpha reliability was found to be moderate $(0.553)$. A high score in the variable indicates more disadvantages of using iPads.

The statistics of the study variables examined are presented in Table 1. Each hypothesis was tested for positive or negative correlation between the study variables (communication, learning, social skills and iPad disadvantages) and the level of iPad usage.

Table 1. Statistics of Study Variables

\begin{tabular}{lllll}
\hline Variable & N & Ave. & Std. dv. & Meaning of High Score \\
\hline Level of Usage & 100 & 2.91 & .38 & High level of iPad usage \\
Communication & 100 & 2.73 & .54 & The iPad improves communication \\
Learning & 100 & 2.95 & .63 & The iPad improves learning \\
Social Skills & 100 & 2.52 & .62 & The iPad improves social skills \\
Disadvantages of iPad Usage & 100 & 2.34 & .29 & Many disadvantages \\
\hline
\end{tabular}

Table 1 shows the number of subjects $(\mathrm{N})$, average, standard deviation, and meaning of a high grade for each of the study variables. The variable averages are relatively similar. The learning average is the highest $(\mathrm{M}=2.95$, $\mathrm{SD}=0.63)$, followed by the level of usage $(\mathrm{M}=2.91, \mathrm{SD}=0.38)$, communication $(\mathrm{M}=2.73, \mathrm{SD}=0.54)$, and social skills $(\mathrm{M}=2.52, \mathrm{SD}=0.62)$. The lowest average is the average number of disadvantages of iPad usage ( $\mathrm{M}$ $=2.34, \mathrm{SD}=0.29$ ).

To test the research hypotheses, we chose to use a Pearson correlation significance test. We chose this test because it enables us to find the correlations between the different variables in the study. The Pearson correlation coefficients between the research variables are marked by $r$, and $p$ is the significance of the correlation between the level of iPad usage and all the other research variables.

The first research hypothesis concerns a positive correlation between the level of iPad usage and how it improves the communication of children who suffer from ASD. This research hypothesis was confirmed: $r=0.44, p<0.01$. A significant positive correlation between the variables was found, indicating that the higher the level of usage, the more important the role of the iPad in improving the child's communication skills.

The second research hypothesis is that the children's level of learning increases with the increase in iPad usage. This hypothesis was also confirmed: $\mathrm{r}=0.52, \mathrm{p}<0.01$. That is, there is a significant positive correlation between the use of iPads and a higher level of learning. This correlation is reflected in the fact that an increase in iPad usage leads to an increase in learning ability.

The third research hypothesis concerns the negative effect of using iPads on social ability. This research hypothesis was not confirmed, since, contrary to the hypothesis, the correlation between the variables was found to be positive and significant: $r=0.29, \mathrm{p}<0.01$. Therefore, an increase in the use of iPads contributes to an increase in social skills, contrary to the research hypothesis.

The fourth research hypothesis concerns the relationship between the level of iPad usage and its disadvantages; specifically, outbursts and obsessions following iPad usage. This research hypothesis was also confirmed. A positive significant correlation was found between the level of iPad usage and the number of outbursts and level of obsession with the iPad: $r=0.32, p<0.01$. Therefore, an increase in iPad usage is associated with the increase in the level of outbursts and obsessions with the device.

\section{Discussion}

The purpose of the current study is to examine the effect of iPad usage in the special-education system on children with ASD. In addition, this study examines the variables of communication, learning, and social abilities and how they are affected by iPad usage in children with ASD. We also examined possible negative effects of iPad usage, such as outbursts and iPad obsession. 
The first hypothesis was confirmed-there is a positive correlation between the level of iPad usage and the way it improves the communication skills of children with ASD. Previous studies show that iPads serve as an important tool for communication and even facilitate communication between teachers and students (Alhajeri et al., 2017).

The second hypothesis is that with the increase in iPad usage, the level of learning is higher. The findings show that there is a significant positive correlation between iPad usage and a higher level of learning. This correlation is reflected in the fact that an increase in iPad usage leads to an increase in learning ability. These findings are consistent with previous studies that suggest the use of iPads as a learning tool in a number of basic fields. The hypothesis was confirmed (Burton et al., 2013).

Contrary to the third hypothesis that iPads negatively affect social ability, a significant positive correlation was found between the variables. That is, an increase in iPad usage contributes to an increase in social skills. The conclusion of this study is that iPads serve as a significant tool for implementing a social model that allows people with ASD to integrate into their social environment. Some studies disagree with this conclusion, and show a number of disadvantages of iPad usage, including the possibility that it may decrease the ability of children with ASD to maintain eye contact or attract people's attention. The hypothesis was not confirmed (Flores et al., 2012; Nitsan, 2015).

The fourth hypothesis concerns the correlation between the level of iPad usage and its disadvantages, and was specifically examined by physical and behavioral phenomena: outbursts and obsessions following iPad usage. A positive significant correlation was found between the level of usage and the number of outbursts and level of obsession with the iPad. This shows that an increase in iPad usage is associated with the increase in outbursts and obsession with the device. Previous studies show that, contrary to our hypothesis, iPads raise the level of play and decrease the number of problem behaviors. The hypothesis was confirmed (Clarke \& Kim, 2015).

\subsection{Research Limitations and Recommendations for Further Research}

During the research, our main limitation was in finding subjects to answer the questionnaire and gaining their cooperation. We had difficulty in finding people from the field of special education, and used social networks as a significant source for finding them. Another limitation we encountered was finding a questionnaire specific to the topic of our research. Previous research is mainly based on experiments, and very few include questionnaires. Further research is needed to more deeply examine technology, which has entered every aspect of our lives, and find additional ways it can be used to make life easier for children with ASD.

\section{Conclusion}

The findings of the current study contribute to a better understanding of the importance of using iPads in the special-education system among children with ASD. The study shows that the significant effect of iPads is manifested in a variety of areas-learning, communication and social abilities. Also, further research on the topic can more thoroughly examine the disadvantages of iPad usage discussed in this study.

\section{Acknowledgements}

The authors wish to thank Batya Carroll and Efrat Ben Moshe, undergraduate students of social sciences at Ariel University, for their assistance in the data collection for this study.

\section{References}

Alhajeri, O., Anderson, J. A., \& Alant, E. (2017). Effectiveness of the use of iPads to enhance communication and learning for students with autism: A systematic review. International Journal of Technology and Inclusive Education, 6(1), 1041-1055. https://doi.org/10.20533/ijtie.2047.0533.2017.0132

Barak, M., \& Peleg, R. (1998). From vacational education to technological education: The meaning, need and high status of technological education in the eyes of students. Studies in Education, 3(2), 111-142. (in Hebrew)

Burton, C. E., Anderson, D. H., Prater, M. A., \& Dyches, T. T. (2013). Video self-modeling on an iPad to teach functional math skills to adolescents with austim and intellectual disability. Focus on Autism and Other Developmental Disabilities, 28(2), 67-77. https://doi.org/10.1177/1088357613478829

Cohen, L. (2015). Teaching and learning in a high-technological environment. In Ministry of Education, Paths for Meaningful Teaching: An Array of Practical Models for Meaningful Tecahing (51-56). Retrieved from http://meyda.education.gov.il/files/MinhalPedagogy/netivim.pdf (in Hebrew)

Davidovitch, N., Yavich, R., \& Keller, N. (2014). Mathematics And Experiential Learning Are They Compatible?. Journal of College Teaching \& Learning (TLC), 11(3), 135-148. 
https://doi.org/10.19030/tlc.v11i3.8759

Evyasar, G., Ronen, C., Ehrlich, D., \& Heiman, T. (2015). Issues in special education: The essence of special education; intellectual disability (Vol. 1). Ra'anana, Israel: The Open University of Israel. (in Hebrew)

Flores, M., Musgrove, K., Renner, S., Hinton, V., Strozier, S., Franklin, S., \& Hill, D. (2012). A comparison of communication using the Apple iPad and a picture-based system. Augmentative and Alternative Communication, 28(2), 74-84. https://doi.org/10.3109/07434618.2011.644579

Gorbatov, R., \& Ben-Moshe, E. (2019). Autistic People. In Ministry of Labor, Social Affairs and Social Services, Social Services Overview 2009 (441-456). Retrieved from

https://www.gov.il/blobFolder/reports/molsa-social-services-review-2009/he/SocialServicesReview_2009_ molsa-disabilities-part4-2009.pdf (in Hebrew)

Gould, M. (2015). Using iPads to increase on-task behavior of students with autism (Master's thesis, Rowan University, Glassboro, New Jersey, USA). Retrieved from https://rdw.rowan.edu/cgi/viewcontent.cgi?article=1510\&context=etd

Kim, S., \& Clarke, E. (2015). Case study: An iPad-based intervention on turn-taking behaviors in preschoolers with autism. Behavioral Development Bulletin, 20(2), 253-264. http://dx.doi.org/10.1037/h0101314

King, A. M., Thomeczek, M., Voreis, G., \& Scott, V. (2014). IPad® use in children and young adults with autism spectrum disorder: An observational study. Child Language Teaching and Therapy, 30(2), 159-173. https://doi.org/10.1177/0265659013510922

Lord, C., \& Bishop, S. L. (2010). Autism spectrum disorders and commentaries: Diagnosis, prevalence, and services for children and families. Social Policy Report, 24(2), 1-27. https://doi.org/10.1002/j.2379-3988.2010.tb00063.x

Manny-Ikan, E., Berger-Tikochinski, T., Bashan, Z., \& Wolf, I. (2015). Using tablets in the class room-Implications for teaching and learning [PDF file]. In Y. Eshet-Alkalai Editor, I. Blau Editor, A. Caspi Editor, N. Geri Editor, Y. Kalman Editor \& V. Silber-Varod Editor (Eds.), Proceedings of the 10th Chais Conference for the Study of Innovation and Learning Technologies: Learning in the Technological Era (pp. 90-98). Ra'anana: The Open University of Israel. Retrieved from https://www.openu.ac.il/innovation/chais2015/download/Chais2015.pdf

McNaughton, D., \& Light, J. (2013). The iPad and mobile technology revolution: Benefits and challenges for individuals who require augmentative and alternative communication. Augmentative and Alternative Communication 29(2), 107-116. https://doi.org/10.3109/07434618.2013.784930

Nitsan, N. (2015). The iPad revolution [PDF file]. Retrieved from https://www.beitissie.org.il/kb/wp-content/uploads/2015/05/-------o--.pdf (in Hebrew)

Ostashewski, N., \& Reid, D. (2010). IPod, iPhone, and now iPad: The evolution of multimedia access in a mobile teaching context. In J. Herrington Editor \& C. Montgomerie Editor (Eds.), Proceedings of ED-MEDIA 2010-World Conference on Educational Multimedia, Hypermedia \& Telecommunications (pp. 2862-2864). Toronto, Canada: Association for the Advancement of Computing in Education (AACE). Retrieved from https://www.learntechlib.org/primary/p/35046/

Sharon, M. (2010). The rights of autistic students in special-education institutions affiliated with the Ministry of Education [Microsoft Word document]. ALUT-The Israeli Society for Autistic Children. Retrieved from https://storage.cet.ac.il/SharvitNew/Storage/1257335/504643.doc (in Hebrew)

Van der meer, L., Achmadi, D., Cooijmans, M., Didden, R., Lancioni, G. E., O'Reilly, M. F., ... Sigafoos, J. (2015). An iPad-based intervention for teaching picture and word matching to a student with ASD and severe communication impairment. Journal of Developmental and Physical Disabilities 27(1), 67-78. https://doi.org/10.1007/s10882-014-9401-5

Waisblay, E. (2015). Education for children with special needs in Israel-data and main issues [PDF file]. Retrieved from https://fs.knesset.gov.il/globaldocs/MMM/951207dc-1277-e511-80d1-00155d0ad6b2/2_951207dc-1277-e5 11-80d1-00155d0ad6b2_11_8781.pdf (in Hebrew) 


\section{Appendix A}

\section{Questionnaire}

This questionnaire includes socio-demographic items and items to rate on a scale. In each item, mark your opinion (1-not at all, 2-slightly, 3-very much, 4-extremely).

Please mark the correct answer for you:

a. Gender-male/ female

b. Education-primary/ high-school/ bachelor's degree/ master's degree

c. Job-teacher/ speech therapist/ occupational therapist/ behavior analyst/ university or college student/ national service/ teaching assistant

d. How long have you been in the current job? Less than a year/ one year/ five years/ ten years or more

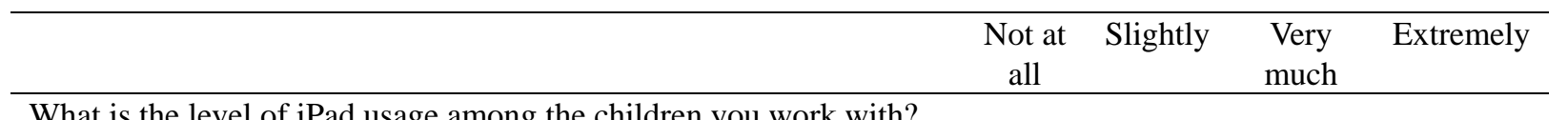

What is the level of iPad usage among the children you work with?

To what extent do you want to change the amount of time that the children spend using iPads?

The iPads are used during free time between the planned activities

The iPad is used when the child wants to communicate with someone

The iPad is used as a casual activity

The school's iPad programs match the school curriculum

The iPads are meant to be used for playing games, and I don't want them to be part of the curriculum

The iPads serve as a means for strengthening children's skills

The iPads are incorporated into the extracurricular school activities

The children enjoy using iPads at school

The level of the children's attention and concentration when using

iPads is usually greater than during other activities

To what extent, in your opinion, does iPad usage contribute to eye contact?

To what extent, in your opinion, does iPad usage increase the ability of the children to follow instructions?

To what extent, in your opinion, do iPads increase the understanding of arithmetic?

To what extent, in your opinion, is there improvement in interpersonal communication as a result of iPad usage?

To what extent, in your opinion, do iPads improve language skills?

The children use the iPads on their own, with no help

The use of iPads increases student involvement

The use of iPads provides an optimal learning experience

The use of iPads increases children's interest in learning

The use of iPads causes students to want to learn more

The use of iPads increases student motivation

The use of iPads increases the interaction between students

The use of iPads increases the interaction between students and staff

The use of iPads is an effective substitute for augmentative and alternative communication

The number of outbursts caused by iPad usage

The degree of obsession with iPads

In your opinion, are iPads used in a positive manner?

Do iPads lead to lack of communication between children and their

surrounding environment?

The iPads are used according to a predetermined plan 


\section{Appendix B}

\section{Descriptive Statistics}

Table B1. Education

\begin{tabular}{llllll}
\hline Education & Frequency & Percent & Valid Percent & Cumulative Percent \\
\hline Valid & Primary & 34 & 34.0 & 34.0 & 34.0 \\
& Bachelor's degree & 45 & 45.0 & 45.0 & 79.0 \\
& Master's degree & 21 & 21.0 & 21.0 & 100.0 \\
& Total & 100 & 100.0 & 100.0 & \\
\hline
\end{tabular}

Table B2. Jobs

\begin{tabular}{llllll}
\hline Job & & Frequency & Percent & Valid Percent & Cumulative Percent \\
\hline Valid & Teacher & 29 & 29.0 & 29.0 & 29.0 \\
& Speech-language therapist & 1 & 1.0 & 1.0 & 30.0 \\
& Occupational therapist & 3 & 3.0 & 3.0 & 33.0 \\
& University or college student & 9 & 9.0 & 9.0 & 42.0 \\
& National Service & 31 & 31.0 & 31.0 & 73.0 \\
& Behavior analyst & 13 & 13.0 & 13.0 & 86.0 \\
& Teaching assistant & 14 & 14.0 & 14.0 & 100.0 \\
& Total & 100 & 100.0 & 100.0 & \\
\hline
\end{tabular}

Table B3. Period of time in the job

\begin{tabular}{llllll}
\hline \multicolumn{2}{l}{ Period of time } & Frequency & Percent & Valid Percent & Cumulative Percent \\
\hline Valid & Less than a year & 9 & 9.0 & 9.1 & 9.1 \\
& Between 1 and 5 years & 52 & 52.0 & 52.5 & 61.6 \\
& Between 5 and 10 years & 20 & 20.0 & 20.2 & 81.8 \\
& More than 10 years & 18 & 18.0 & 18.2 & 100.0 \\
& Total & 99 & 99.0 & 100.0 & \\
Missing & 999.00 & 1 & 1.0 & & \\
\hline Total & 100 & 100.0 & & \\
\hline
\end{tabular}

Table B4. Gender

\begin{tabular}{llllll}
\hline Gender & & Frequency & Percent & Valid Percent & Cumulative Percent \\
\hline Valid & Female & 95 & 95.0 & 95.0 & 95.0 \\
& Male & 5 & 5.0 & 5.0 & 100.0 \\
& Total & 100 & 100.0 & 100.0 & \\
\hline
\end{tabular}

Table B5. Reliability statistics

\begin{tabular}{ll}
\hline Cronbach's Alpha & N (no. of Items) \\
\hline .683 & 8 \\
\hline
\end{tabular}

Table B6. Reliability statistics

\begin{tabular}{ll}
\hline Cronbach's Alpha & N (no. of Items) \\
\hline .840 & 7 \\
\hline
\end{tabular}

Table B7. Reliability statistics

\begin{tabular}{ll}
\hline Cronbach's Alpha & $\mathrm{N}$ (no. of Items) \\
\hline .569 & 3 \\
\hline
\end{tabular}


Table B8. Reliability statistics

\begin{tabular}{ll}
\hline Cronbach's Alpha & $\mathrm{N}$ (no. of Items) \\
\hline .553 & 5 \\
\hline
\end{tabular}

Table B9. Reliability statistics

\begin{tabular}{ll}
\hline Cronbach's Alpha & N (no. of Items) \\
\hline .679 & 5 \\
\hline
\end{tabular}

Table B10. Descriptive statistics of the research variables

\begin{tabular}{llllll}
\hline & $\mathrm{N}$ & Minimum & Maximum & Mean & Std. Deviation \\
\hline UseAV & 100 & 1.63 & 3.75 & 2.9100 & .38766 \\
ComunicationAv & 100 & 1.00 & 4.00 & 2.7360 & .54226 \\
LearningAv & 100 & 1.00 & 4.00 & 2.9583 & .63801 \\
SocialAv & 100 & 1.00 & 4.00 & 2.5267 & .62348 \\
DisordersAv & 100 & 1.67 & 3.00 & 2.3417 & .29718 \\
Valid N (listwise) & 100 & & & & \\
\hline
\end{tabular}

Table B11. Pearson correlation coefficients

\begin{tabular}{|c|c|c|c|c|c|c|}
\hline & & UseAV & Comunication $A v$ & Learning Av & SocialAv & Disorders1Av \\
\hline \multirow[t]{4}{*}{ UseAV } & Pearson & 1 & $.444^{* *}$ & $.525^{* *}$ & $.294^{* *}$ & $.322^{* *}$ \\
\hline & Correlation & & & & & \\
\hline & Sig. (2-tailed) & & .000 & .000 & .003 & .001 \\
\hline & $\mathrm{N}$ & 100 & 100 & 100 & 100 & 100 \\
\hline \multirow[t]{4}{*}{ ComunicationAv } & Pearson & $.444^{* *}$ & 1 & $.681^{* *}$ & $.621^{* * *}$ & -.028 \\
\hline & Correlation & & & & & \\
\hline & Sig. (2-tailed) & .000 & & .000 & .000 & .784 \\
\hline & $\mathrm{N}$ & 100 & 100 & 100 & 100 & 100 \\
\hline \multirow[t]{3}{*}{ LearningAv } & $\begin{array}{l}\text { Pearson } \\
\text { Correlation }\end{array}$ & $.525^{* *}$ & $.681^{* *}$ & 1 & $.576^{* *}$ & .123 \\
\hline & Sig. (2-tailed) & .000 & .000 & & .000 & .221 \\
\hline & $\mathrm{N}$ & 100 & 100 & 100 & 100 & 100 \\
\hline \multirow[t]{3}{*}{ SocialAv } & $\begin{array}{l}\text { Pearson } \\
\text { Correlation }\end{array}$ & $.294^{* *}$ & $.621^{* * *}$ & $.576^{* *}$ & 1 & -.082 \\
\hline & Sig. (2-tailed) & .003 & .000 & .000 & & .417 \\
\hline & $\mathrm{N}$ & 100 & 100 & 100 & 100 & 100 \\
\hline \multirow[t]{3}{*}{ Disorders1Av } & $\begin{array}{l}\text { Pearson } \\
\text { Correlation }\end{array}$ & $.322^{* *}$ & -.028 & .123 & -.082 & 1 \\
\hline & Sig. (2-tailed) & .001 & .784 & .221 & .417 & \\
\hline & $\mathrm{N}$ & 100 & 100 & 100 & 100 & 100 \\
\hline
\end{tabular}

** Correlation is significant at the 0.01 level (2-tailed).

\section{Copyrights}

Copyright for this article is retained by the author(s), with first publication rights granted to the journal.

This is an open-access article distributed under the terms and conditions of the Creative Commons Attribution license (http://creativecommons.org/licenses/by/4.0/). 